\title{
"I have learned to see"
}

Previously published at www.cmaj.ca

$\mathrm{W}$ hen Dr. Wilder Penfield gives you some personal advice, it's not something you're likely to forget - although it may take a while to hit home. It was nearly 30 years after he had worked as a budding researcher at the Montréal Neurological Institute that Dr. Sean B. Murphy, then the ophthalmologist-inchief at the Royal Victoria Hospital and chair of the McGill Department of Ophthalmology, started to consider what he might do when he retired. And Penfield's advice from many years earlier rang in his ears: "Think about starting a second career long before you retire."

So, Murphy took up drawing and painting in his mid-50s. He hadn't wielded a paint brush since childhood, but art had always been a vital part of his life. His parents were both New York printmakers of considerable repute and in his youth he had visited numerous art museums. He kept up this habit during adulthood and became an active member of the Montréal Museum of Fine Arts, then its president (1968-1978) as well as a board member of the Canada Council for the Arts.

Now in his mid-80s, Murphy has published a book about his 30-year journey into drawing and painting entitled, Dare to Draw $•$ La passion du dessin (Visual Arts Centre/McClure Gallery; 2008).

Starting with a colourful description of the challenges and frustrations of learning to draw and paint with watercolours, he goes on to describe the great pleasure he derives from the pursuit. With an archive of 56 sketchbooks documenting his jourI ney in visual art, Murphy has realized an important side benefit: "I have learned to see, to really see. For an eye surgeon, that is no small disclosure."

In the book, which features a forward by renowned Canadian artist Alex Colville, Murphy describes a typical

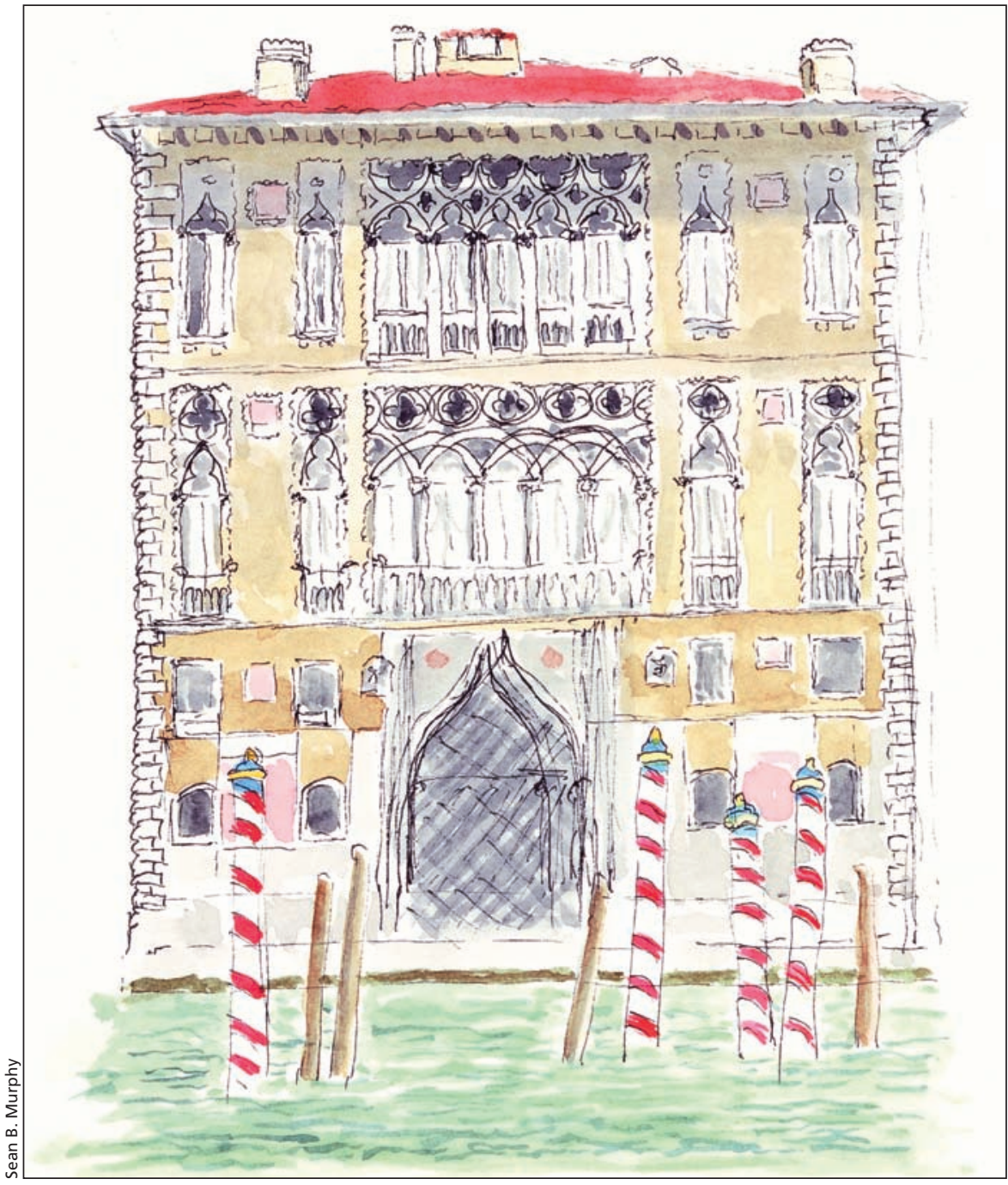

Sean B. Murphy. Grand Canal Palazzo, Venice. The artist writes: "A comfortable bench beside the Grand Canal allowed me to leisurely observe this magnificent palazzo. I knew right away I had to sketch it. After an hour I remained another hour simply enjoying the sight and talking to passers-by."

experience of drawing that took place in a church in Mexico: "Alone, surrounded by rich golden decorations, I sat and thought: How to capture the feeling of this interior built to the glory of God? I began by observing, contemplating and absorbing the quiet atmosphere. The urge to sketch took over; I left aware of being moved by a deeper feeling than would have occurred had I not sketched." The resulting intricate ink drawing of the Santo Domingo Church in Oaxaca is one of many reproductions of his artwork contained in the book, which also features doodles, pen and pencil drawings, travel sketches and watercolours. The works range from fairly simple sketches to elaborate paintings, executed with sensuous 


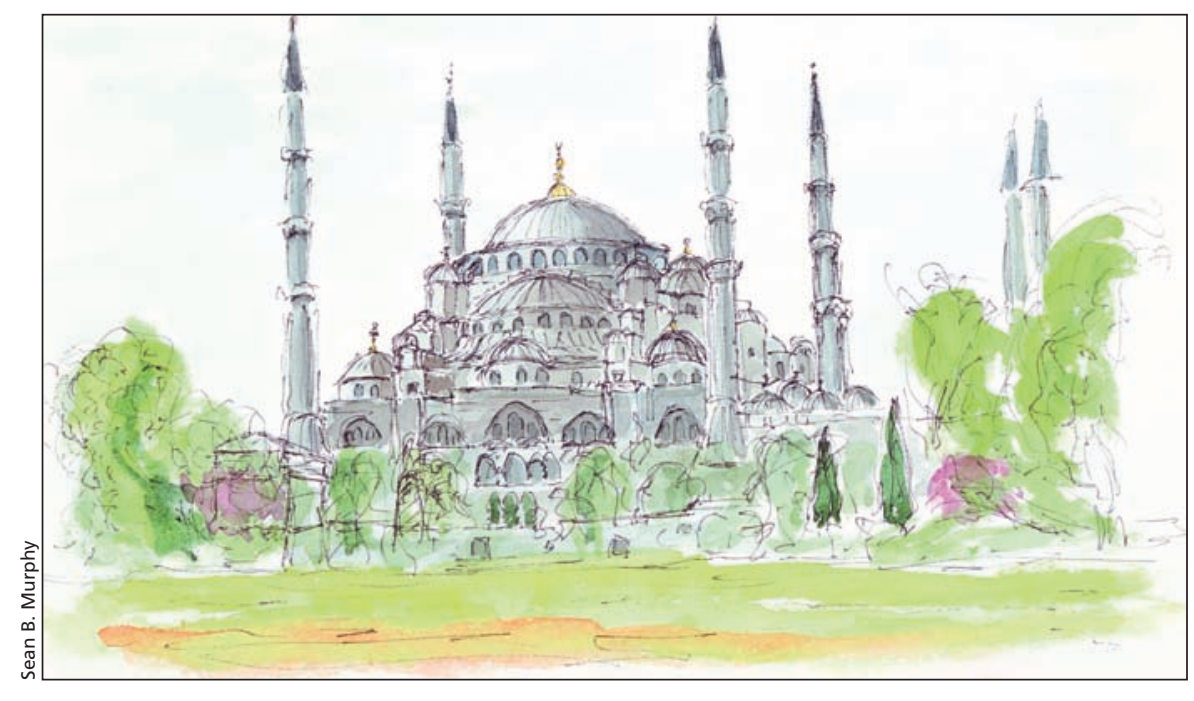

Sean B. Murphy. Blue Mosque, Istanbul. Constructed in the late 17th century, the Blue Mosque faces the Hagia Sofia Mosque. Half-way between the two are several benches for artists. "This is one of the finest sketching sites I have found anywhere," writes Murphy.

line-work and delicate application of colour. Although modest about his artistic achievements, many of Murphy's works exhibit considerable maturity of personal style. Some evoke the work of the celebrated New Yorker illustrator Jean-Jacques Sempé.

Murphy decided to write this book "not because I'm a great artist but precisely because I'm not a great artist." His objective was to inspire others to embark on their own journey of drawing and painting.
The book is a good primer for anyone who has the urge to draw or paint, with separate chapters on the basics of drawing and painting, the skinny on what classes to take, the kinds of materials required and the importance of carrying around a sketchbook. The text is part how-to, with a liberal sprinkling of anecdotes of his art adventures and cogent observations about art: "Surprisingly, drawing is a language that has not changed very much throughout the centuries ... [even though] Art

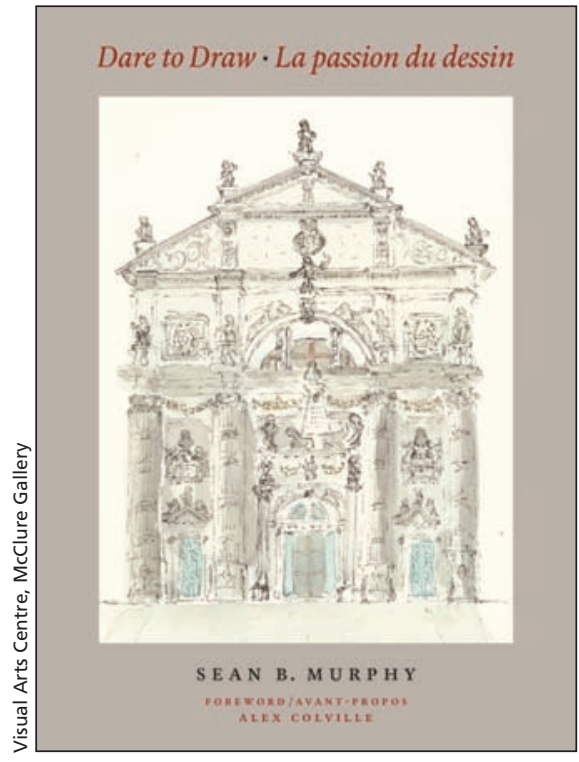

styles change constantly," he writes.

Murphy's enthusiasm for his second career is obvious. "I still wake each morning, eager to capture on paper with my pencil or brush, a little corner of the world's inordinate beauty, as best I know how."

\section{Stuart Kinmond MArch \\ Architect and artist \\ Ottawa, Ont.}

After working in architecture for 30 years, Stuart Kinmond is now in the midst of his second career — as a visual artist.

\section{ESSAY}

\section{Humility and the practice of medicine: tasting humble pie}

\section{Previously published at www.cmaj.ca}

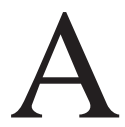
s Scottish author J.M. Barrie wrote, "Life is a long lesson in humility." At first glance, the topics of medicine and humility would seem an unlikely pairing. After all, training for certainty in the practice of medicine - the slow but steady relinquishment of humility - begins in medical school.

Along the way, ignorance is replaced by knowledge and doubt with assurance. In his book The Silent World of Doctor and Patient, Jay Katz states: "Socialization of physicians reinforces the univer- sal human tendency to turn away from uncertainty," letting physicians assume a role as "the bearers of certainty."

But to be humble means to appreciate the limits of your abilities, understanding and importance. For physicians, humility distinguishes between knowing what illness the patient has and what it means, and understanding how it feels to have it. Humility differentiates what is clinically indicated from what treatment choices patients deem appropriate; it also separates knowing what should happen within specified clinical circumstances from what does happen.

Sir William Osler understood that while some things can be known, others must be inferred or experienced. One morning, Osler was discovered by a colleague, "struggling in the effort to pass a stomach tube upon himself, resulting in the ordinary gagging and retching which such a procedure produces in one unaccustomed to it." When asked what he was doing, he replied: "Well, we often pass these on people, and I thought we ought to find out what it feels like ourselves." Wisdom led Osler to appreciate those things that characterize human vulnerability and patienthood; humility helped him understand that there are aspects of human suffering that are not 